\title{
TGF $\beta$ family mimetic peptide promotes proliferation of human hair follicle dermal papilla cells and hair growth in C57BL/6 mice
}

Yeong Min Choi ${ }^{1}$, Soo Young Choi ${ }^{1}$, Hyonmin Kim ${ }^{1}$, Jeongmin $\mathrm{Kim}^{1}{ }^{1}$, Mun Sang Ki ${ }^{2}$, In-sook An ${ }^{1}$ and Jinhyuk Jung ${ }^{1 *}$

\begin{abstract}
Background: Hair follicle morphogenesis is orchestrated by bidirectional ectodermal-mesenchymal signaling. In particular, TGF $\beta$ (transforming growth factor-beta) family is an important regulator of hair follicle formation and cycling. In this study, we investigated the effect of TGF $\beta$ family mimetic peptide (dermal papilla stem cell activator-1, DPS-1) on activation of hair follicle formation.

Methods: Cell viability, cell cycle, and mRNA expression of human dermal papilla (HDP) cells after DPS-1 or vehicle treatment were determined, and histological analysis of hair cycle was performed from the mouse dorsal back skin after DPS-1 or vehicle administration.

Results: DPS-1 promotes proliferation from 3D sphered HDP cells, but not from 2D cultured HDP cells. DPS-1 induces mRNA expression of genes, which are responsible for hair growth from HDP cells. Moreover, topical administrated DPS-1 stimulates hair growth in mice. Subsequently, histological analysis showed that the diameter and depth of hair follicles were remarkably higher in mice that were administered with DPS-1 compared to vehicle control.
\end{abstract}

Conclusions: DPS-1 promotes proliferation of HDP cells as well as hair growth partly via activation of WNT/ $\beta$-catenin signaling.

Keywords: TGFß mimetic peptide, DPS-1, Dermal papilla, Hair follicle development

\section{Background}

A hair follicle (HF) is composed of several distinct epithelial and mesenchymal lineages (Schmidt-Ullrich and Paus 2005). Each stage of hair cycle is regulated by signaling between the epithelium and mesenchymal cells that are located at the base of HF (Ehama et al. 2007). Dermal papilla (DP), a specialized mesenchymal population of HF, plays vital roles in HF morphogenesis and cycling (Miranda-Vilela et al. 2014). In particular, growth factors secreted by DP cells directly promote proliferation as well as differentiation of surrounding matrix cells. Consequently, DP cells stimulate hair stem cells to initiate

\footnotetext{
* Correspondence: Jungjh.lab@gmail.com

${ }^{1}$ Korea Institute for Skin and Clinical Sciences, Gene Cell Pharm Corporation, 6F, Tower A, 25, Beobwon-ro 11-gil, Songpa-gu, Seoul, Republic of Korea Full list of author information is available at the end of the article
}

HF generation and new hair growth cycle (Kang et al. 2010). $\mathrm{WNT} / \beta$-catenin and bone morphogenetic protein (BMP) pathway are one of the crucial signaling for HF generation (Kishimoto et al. 2000). There are reports that WNT/ $\beta$-catenin is essential for proliferation and differentiation of hair shaft (Millar et al. 1999; Cotsarelis et al. 1990). Moreover, WNT/ $\beta$-catenin signaling by DP cells is required to maintain hair inductivity (Soma et al. 2012). Additionally, BMP from transforming growth factor $\beta$ (TGF $\beta$ ) superfamily is important for HF development (Millar 2002; Botchkarev and Paus 2003; Rendl et al. 2008). Previous studies showed that WNT/ $\beta$-catenin and TGF $\beta$ family interact to regulate the transcription of a number of genes, which is related with HF formation. Furthermore, there are synergistic effects between $\mathrm{WNT} / \beta$-catenin and TGF $\beta$ signaling pathway in various cellular functions 
including tumorigenesis and stem cell differentiation (Choi et al. 2017). Because TGF $\beta$ family is crucial for HF morphogenesis as well as hair cycle, we developed synthetic peptides which are structurally similar to endogenous human TGF $\beta$ family but possess unique sequences, which we named, dermal papilla stem cell activator-1 (DPS-1). To investigate the function of DPS-1 on HF formation and cycle, we determined whether DPS-1 promotes human dermal papilla (HDP) cell proliferation as well as WNT/ $\beta$-catenin signaling. Moreover, we determined stimulatory effects on hair growth by DPS-1 from C57BL/6 mice.

\section{Materials and methods}

\section{Synthesis of TGF $\beta$ family mimetic peptide}

A synthetic peptide (DPS-1), designed based on original protein sequence of TGF $\beta$ family, which is part of receptor-binding sequence, GNCWL. DPS-1 was synthesized using the solid phase peptide synthesis method. Briefly, amino acid (3 equiv), HOBt (3 equiv), and diisopropylcarbodiimide (3 equiv) were added into a DMF solution. After activation, the solution was added to the resin DMF solution and agitated for $4 \mathrm{~h}$. Each gradient coupling reaction in solid phase was repeated until no color change of the resin was monitored in ninhydrin test. After cleavage, the crude peptide was triturated with diethyl ether chilled at $-20{ }^{\circ} \mathrm{C}$ and was centrifuged at $3000 \mathrm{rpm}$ for $10 \mathrm{~min}$. Diethyl ether was decanted, and the crude peptide was dried under nitrogen. The purity of crude peptide $(<95 \%)$ were confirmed by analytical HPLC with a C18 column using a linear gradient of $\mathrm{H}_{2} \mathrm{O}$ and acetonitrile (0-100\% acetonitrile) containing $0.1 \%$ TFA. The resulting product was purified by prep-HPLC with a $\mathrm{C} 18$ column using a water (0.1\% TFA)-acetonitrile (0.1\% TFA) gradient to give DPS-1. DPS-1 was confirmed by MALDI-TOF Mass (Voyager DE-STR, Applied Biosystems, USA, Cal. mass 1335.70, Obs. mass 1335.70).

\section{Cell culture and materials}

Human dermal papilla (HDP) cells were maintained using Dulbecco's modified Eagle medium (DMEM; Hyclone, Logan, UT, USA) with $1 \%$ penicillin/streptomycin $(10,000$ units $/ \mathrm{ml}$ penicillin $\mathrm{G}$ sodium, 10,000 $\mu \mathrm{g} / \mathrm{ml}$ streptomycin; Gibco-BRL/Invitrogen Life Technologies, Gaithersburg, MD, USA) and $10 \%$ fetal bovine serum (FBS; Hyclone) and incubated at $5 \% \mathrm{CO}_{2}$ and $37{ }^{\circ} \mathrm{C}$. Tofacitinib was purchased from Sigma-Aldrich (St. Louis, MO, USA).

\section{Cell viability assay}

$2 \times 10^{3}$ of HDP cells were plated in a 96-well plate and then incubated for $24 \mathrm{~h}$. After $24 \mathrm{~h}$, DPS-1 was treated with indicated concentration for $24 \mathrm{~h}$. Water-soluble tetrazolium salt (WST-1) solution was added and incubated for $20 \mathrm{~min}$. Optical density of each wells were measured at
$450 \mathrm{~nm}$ using a microplate reader iMark (Bio-Rad, Hercules, CA, USA). And the value was calibrated by measuring a reference absorbance at $650 \mathrm{~nm}$.

\section{Quantitative RT-PCR (qRT-PCR)}

Total RNA was extracted from HDP spheres using a TRIzol reagent (Thermo Fisher Scientific, Rockford, IL, USA). The RNA was converted into cDNA with M-MLV reverse transcriptase (Thermo Fisher Scientific). qRT-PCR was performed using a SYBR ${ }^{\text {tux }}$ green PCR master mix (Thermo Fisher Scientific) with a Step OnePlus Real-Time PCR System (Applied Biosystems-Thermo Fisher Scientific). All the above steps were performed according to the manufacturer's protocol. The sequences of the primers used for qRT-PCR are as follows: WNT family member 5A (WNT5A): 5'-TCCACCTTCCTCTTCACACTGA-3' (forward) and 5'-CGTGGCCAGCATCACATC)-3' (reverse); lymphoid enhancer-binding factor-1 (LEF1): $5^{\prime}$-CC CGATGACGGAAAGCAT-3' (forward) and 5'-TCGAGT AGGAGGGTCCCTTGT-3' (reverse); WNT inhibitor factor-1 (WIF1): 5' -TGGCATGGAAGACACTGCAA-3' (forward) and 5' -GGCCTCAGGGCATGTATGA-3' (reverse); GAPDH: 5' -ATCACCATCTTCCAGGAGCGA-3' (forward) and 5'-TTCTCCATGGTGGTGAAGACG-3' (reverse). Each mRNA expression level was calculated using the $2^{-\Delta \Delta C t}$ method and normalized to the expression level of the GAPDH housekeeping gene (Table 1).

\section{Hair growth activity in mice}

Eight-week-old female C57BL mice were purchased from Oriental Bio Co (Seoul, Republic of Korea). After a 7-day acclimation period for being automatically maintained at $21-25{ }^{\circ} \mathrm{C}$ and a relative humidity of $45-65 \%$ with a controlled light-dark cycle, the animals were divided into three randomized groups $(n=8)$ to investigate hair growth-promoting activity of DPS-1. DPS- $1(250 \mu \mathrm{g} / \mathrm{ml})$ or tofacitinib $(500 \mu \mathrm{g} / \mathrm{ml})$ was topically applied on dorsal back daily for 15 days. Reagents used for the hair growth test were dissolved in a vehicle containing $150 \mu \mathrm{l}$ of acetone and $30 \mu \mathrm{l}$ glycerol. All animals were cared for by using protocols approved by the Institutional Animal Care and Use Committee (Konkuk University, Republic of Korea) no. KU16199.

Table 1 The sequences of the primers used for qRT-PCR

\begin{tabular}{lll}
\hline Gene & Forward primers & Reverse primers \\
\hline WNT5A & 5'-TCCACCTTCCTCTTCACACTGA-3' & 5'-CGTGGCCAGCATCACATC)-3' \\
WIF1 & 5'-TGGCATGGAAGACACTGCAA-3' & 5'-GGCCTCAGGGCATGTATGA-3' \\
LEF1 & 5'-CCCGATGACGGAAAGCAT-3' & 5'-TCGAGTAGGAGGGTCCCTTGT-3' \\
GAPDH & 5'-ATCACCATCTTCCAGGAGCGA-3' & 5'-TTCTCCATGGTGGTGAAGACG-3' \\
\hline
\end{tabular}




\section{Statistical analysis}

All data are expressed as mean \pm standard deviation (SD) of three independent experiments. Statistical analyses were conducted using GraphPad Prism 6 software (Graphpad software, San Diego, CA, USA). Data were analyzed using two-tailed Student's $t$ test or one-way analysis of variance (ANOVA) followed by Tukey's multiple comparison post test. $p<0.05$ was considered statistically significant.

\section{Results}

\section{Effect of DPS- 1 on HDP cell proliferation}

Because of previous report that TGF $\beta$ family activates hair cycle by promoting HDP activation, we determined whether DPS-1 promotes HDP growth. To test this, we performed proliferation analysis using WST-1 assay after culture with or without DPS-1. Because of recent report that 3D spheroid culture of HDP enhances hair inductivity as well as cycle compared to conventional 2D culture, 3D spheroid culture is regarded as relevant culture method for HF formation (Guo et al. 2008). Thus, we tested HDP proliferation by DPS-1 on both conventional 2D and 3D spheroid culture. Although DPS-1 does not promote HDP proliferation on conventional 2D (Fig. 1a), 3D spheroid cultured HDP proliferation was promoted by DPS-1 treatment (Fig. 1b). Tofacitinib, which has been reported to promote hair growth, was used as a positive control (Harel et al. 2015). These results indicate that DPS-1 has a proliferative effect on 3D spheroid cultured HDP cells.

\section{Effect of DPS-1 on HDP sphere formation}

We next determined whether DPS-1 increases the sphere size of HDP cells, which is related with hair inductivity.
To test this, microscopic analysis was performed. Self-assembly as well as size of DPS-1-treated HDP spheroids were increased compared to vehicle-treated HDP spheroids (Fig. 2a). We confirmed this result by performing three independent replicate experiments (Fig. 2b). These results demonstrate that DPS-1 promotes the formation of HDP spheroids, which enhances hair growth inductivity.

\section{Effect of DPS-1 on hair growth-related gene expression from HDP cells}

We determined whether DPS-1 regulates mRNA expression including WNT5A, WIF1, and LEF1, which were reported as hair growth-related signature genes (Ohyama et al. 2010; Yang and Cotsarelis 2010), using a quantitative reverse transcriptase PCR (RT-PCR). As a result, DPS-1 increased expression levels of WNT5A (Fig. 3a), WIF1 (Fig. 3b), and LEF1 (Fig. 3c) from 3D spheroid cultured HDP cells. These data indicated that DPS-1 increases spheroid size as well as signature genes of HDP, which is related with HF.

\section{DPS-1 stimulates hair growth in mice}

Finally, we investigated whether DPS-1 stimulates hair growth in mice. To test this, the dorsal back of 8.5-week C57BL/6 mice was shaved and vehicle or DPS-1 topically treated for 15 days. Tofacitinib was used as the positive control, which was previously reported to stimulate hair growth by promoting telogen to anagen transition (Harel et al. 2015). As expected, the entry into anagen was evident within 7 days of treatment with tofacitinib, whereas vehicle-treated mice remained in telogen.
A

Attached dermal papilla cell

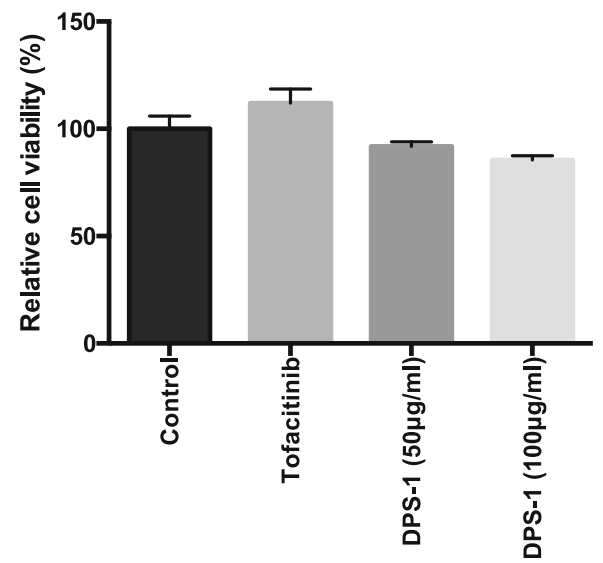

B 3D sphered dermal papilla cell

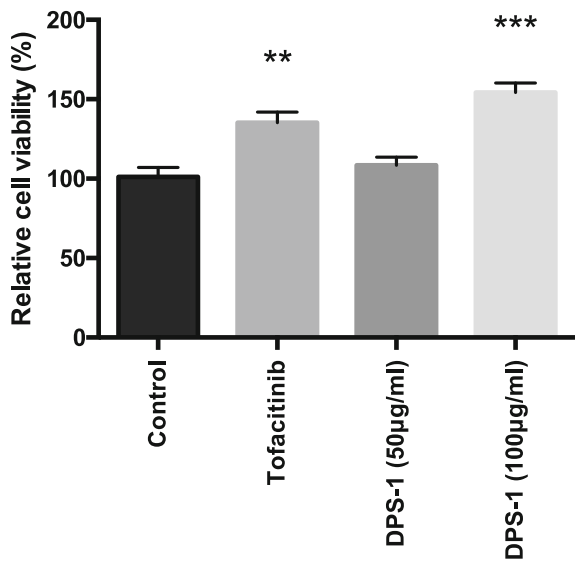

Fig. 1 Effect of DPS-1 on HDP cell proliferation. Effect of DPS-1 treatment on the viability of 2D monolayer cultured (a) and 3D spheroid cultured HDP cells (b). HDP cells were seeded into 96-well plates and pre-treated with various concentrations of DPS-1 (0, 50, $100 \mu \mathrm{g} / \mathrm{ml})$ or tofacitinib (200 nM) for 24 h. Cell viability was measured using WST-1 assay. Data are presented as the mean \pm SD of results from three independent experiments. HDP human dermal papilla, WST-1 water-soluble tetrazolium salt. $p<0.01$ is present as ** and $p<0.005$ is present as *** 
A

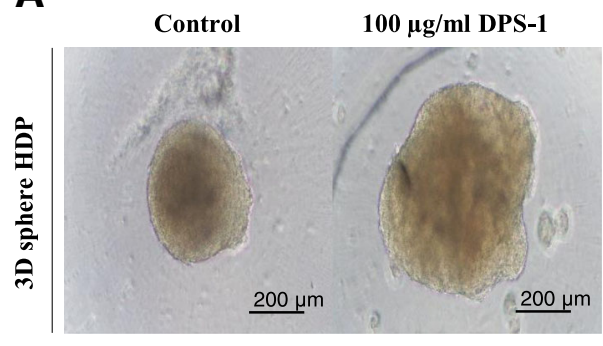

B

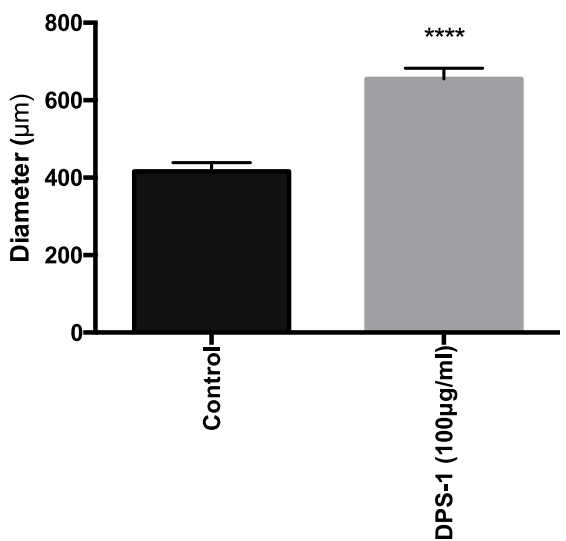

Fig. 2 Effect of DPS-1 on HDP sphere formation. Comparison of spheroid formation of control and DPS-1-treated HDP cells. a Phase images of spheroid of control and DPS-1-treated HDP cells. Images were analyzed after $24 \mathrm{~h}$ of DPS-1 treatment. $\mathbf{b}$ The diameter of spheroid was quantified. Data are presented as the mean \pm SD of results from three independent experiments. $p<0.001$ is present as ****

Interestingly, DPS-1 promoted rapid and intense hair growth in mice with kinetics similar to the tofacitinib (Fig. 4). Histological analysis of the mouse dorsal back skin showed that the diameter and depth of HF were remarkably higher from DPS-1-treated mice compared to the vehicle control.

\section{Discussion}

HF morphogenesis relies on bidirectional signaling events of dermal papilla (DP)-keratinocyte stem cells. Cyclical periods of growth (anagen), regression (catagen), and rest (telogen) are present during HF development (Paus and Cotsarelis 1999). Each hair cycle is tightly regulated by secreted proteins from DP. A recent report shows that
TGF $\beta$ superfamily is involved in HF formation by activating DP through WNT signaling pathway. Thus, we hypothesized TGF $\beta$ mimetic peptide, may serve function as a HF morphogen, could reinforce HF formation.

We observed that DPS-1 increased the viability and spheroid formation of 3D cultured HDP. Indeed, recent studies have shown that hair inductivity of HDP cells are markedly improved in 3D spheroid formation rather than 2D culture (Choi et al. 2017). Therefore, promoting HDP inductivity by DPS-1 may contribute to establish protocol for HF generation in vitro. In addition, DPS-1 induces DP signature genes, which serve critical roles in hair formation. In particular, DPS-1 induces expression of WNT5A, WIF1, and LEF1 in HDP spheres. Our data
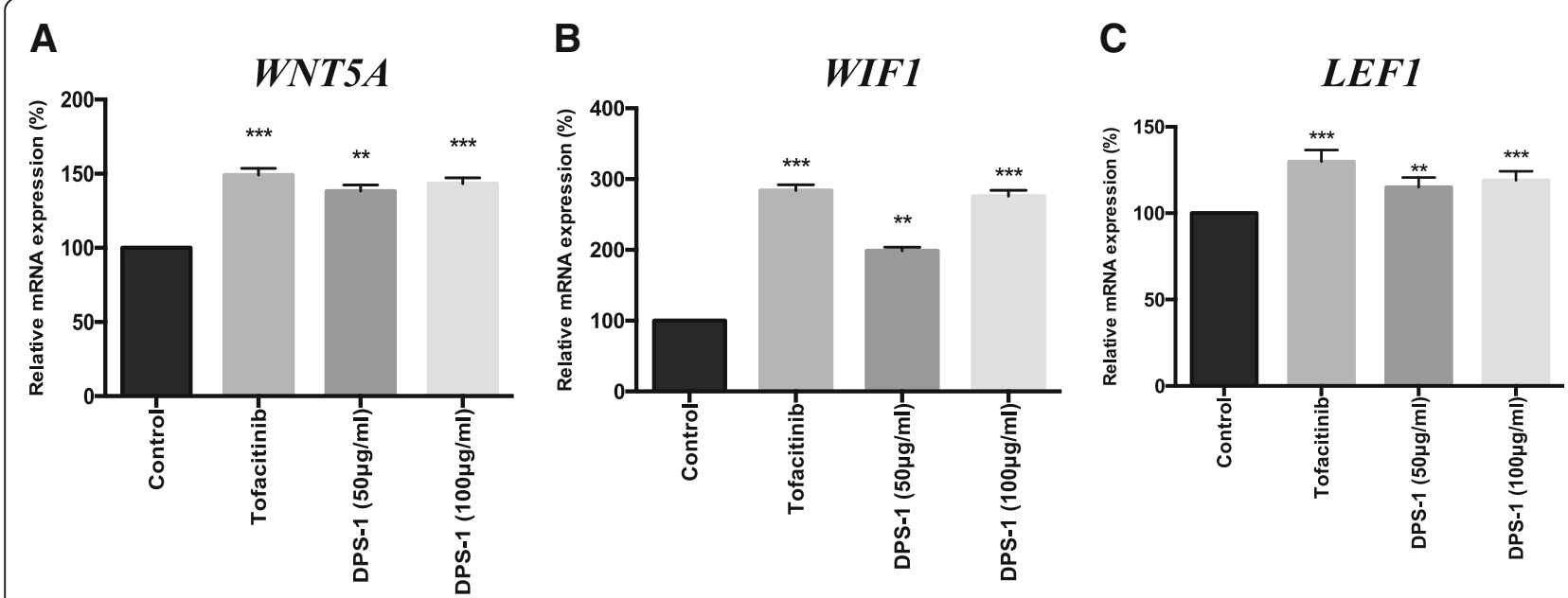

Fig. 3 Effect of DPS-1 on hair growth-related gene expression from HDP cells. HDP cells were seeded into 6-well plates and pre-treated with indicated concentrations of DPS-1 $(100 \mu \mathrm{g} / \mathrm{ml})$ or tofacitinib $(200 \mathrm{nM})$ for $24 \mathrm{~h}$. The gene expression of hair growth-regulating factors, a WNT5A, $\mathbf{b}$ WIF1, $\mathbf{c}$ LEF1, were measured by quantitative real-time PCR using specific primers in HDP cells. GAPDH was used as an internal control. Data are presented as the mean \pm SD of results from three independent experiments. $p<0.01$ is present as ** and $p<0.005$ is present as *** 


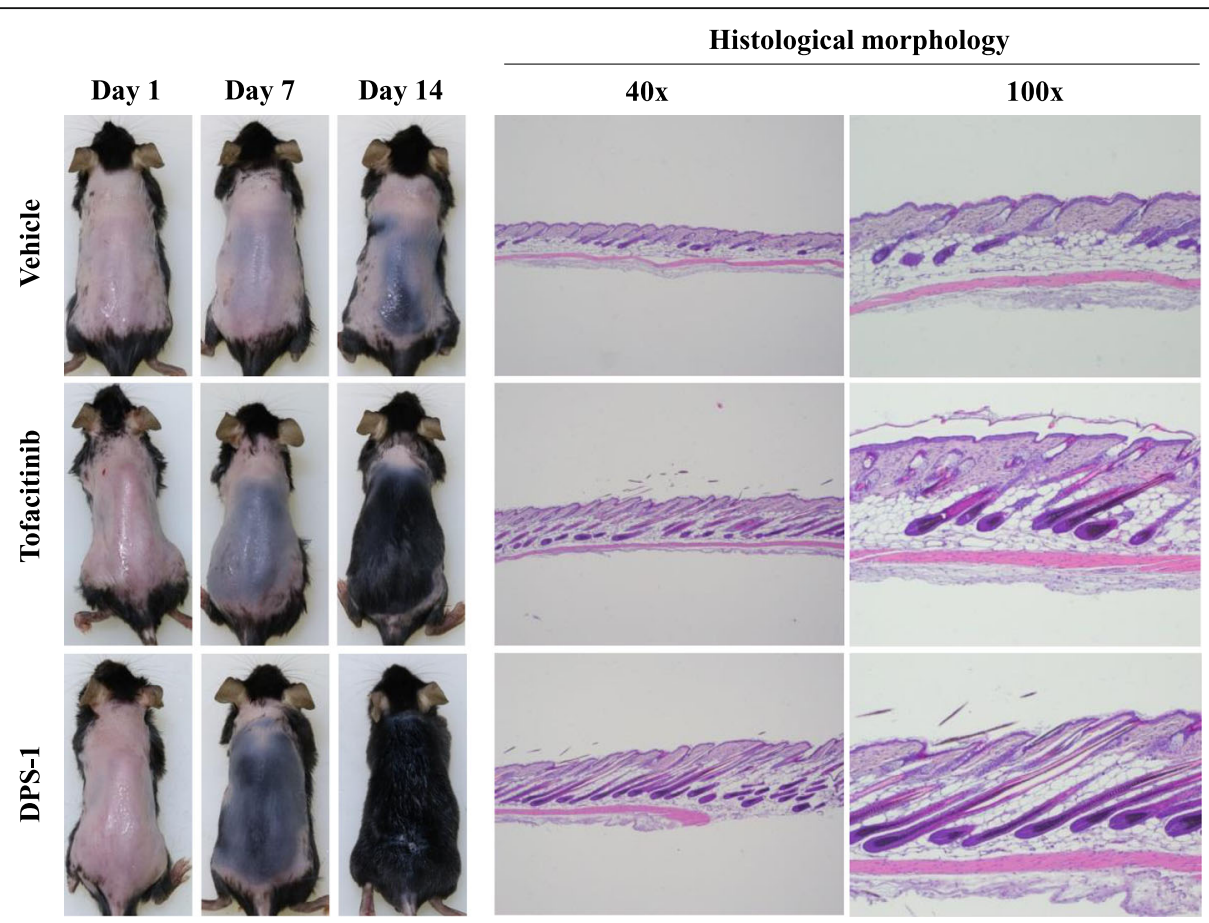

Fig. 4 DPS-1 stimulates hair growth in mice. After synchronizing the telogen phase, shaved dorsal back of C57BL/6 mice was topically treated with vehicle control, DPS-1 $(250 \mathrm{mg} / \mathrm{ml})$ or tofacitinib $(500 \mathrm{\mu g} / \mathrm{ml})$ for 15 days. Typical photos of dorsal skin (left panel), histological analysis (right panel)

suggest that DPS-1 may have similar signaling mechanism to TGF $\beta$ on the DP inductivity although further experiment about off-target effects of DPS-1 remains unclear. Lastly, we observed that topical treatment of DPS-1 stimulates hair growth than vehicle control. In mice, activation of WNT/ $\beta$-catenin signaling induces a pro-growth/anti-quiescence signal during telogen (Telerman et al. 2017), thereby allowing reentry into anagen. Anagen reentry after DPS-1 treatment showed when mice are treated in mid-telogen but not in early telogen, suggesting that DPS-1 may not able to override the quiescence-promoting microenvironment in early telogen.

In summary, our data suggest that DPS-1 may reinforce hair formation property by activation of $\mathrm{WNT} / \beta$-catenin signaling pathway in 3D spheroid cultured HDP cells. And DPS-1 indeed stimulates HF generation in animal model. These data allow us to speculate that DPS-1 treatment may provide novel strategy in treating alopecia in human.

\section{Conclusions}

Our study showed that TGF $\beta$ family mimetic peptide, DPS- 1 , activated $\mathrm{WNT} / \beta$-catenin signaling pathway in spheroid cultured HDP. Moreover, histological analysis by animal model revealed the diameter and depth of the HF in the dermis from DPS-1-treated mice compared to vehicle treated. In conclusion, our study suggests that DPS-1 promotes proliferation of dermal papillae and stimulates hair growth partly via activation of WNT/ $\beta$-catenin signaling of hair follicular cells.

\section{Abbreviations}

BMP: Bone morphogenetic protein; DP: Dermal papilla; DPS-1: Dermal papilla stem cell activator-1; HDP: Human dermal papilla; HF: Hair follicle;

LEF1: Lymphoid enhancer-binding factor-1; qRT-PCR: Quantitative real-time polymerase chain reaction; TGF $\beta$ : Transforming growth factor $\beta$; WIF1: WNT inhibitor factor-1; WNT5A: WNT family member 5A; WST-1: Water-soluble tetrazolium salt

\section{Acknowledgements \\ Not applicable}

\section{Funding}

Not applicable

Availability of data and materials

Not applicable

\section{Authors' contributions}

YMC conducted the study and drafted the manuscript. All authors analyzed the data and reviewed the literatures. YMC, SYC, HK, JK, MSK, IA, and JJ wrote the manuscript. All authors read and approved the final manuscript.

Ethics approval and consent to participate

All animals were cared for by using protocols approved by the Institutional Animal Care and Use Committee (Konkuk University, Republic of Korea) no. KU16199.

Consent for publication

Not applicable

Competing interests

The authors declare that they have no competing interests. 


\section{Publisher's Note}

Springer Nature remains neutral with regard to jurisdictional claims in published maps and institutional affiliations.

\section{Author details}

'Korea Institute for Skin and Clinical Sciences, Gene Cell Pharm Corporation, 6F, Tower A, 25, Beobwon-ro 11-gil, Songpa-gu, Seoul, Republic of Korea. ${ }^{2} \mathrm{NB}$ Clinic, Ansan, Republic of Korea.

Received: 14 June 2018 Accepted: 9 August 2018

\section{Published online: 07 September 2018}

\section{References}

Botchkarev VA, Paus R. Molecular biology of hair morphogenesis: development and cycling. Mol Dev Evol. 2003;298:164-80.

Choi YM, An A, Lee J, Lee JH, Lee JN, Kim YS, Ahn KJ, An IS, Bae S. Titrated extract of Centella asiatica increases hair inductive property through inhibition of STAT signaling pathway in three-dimensional spheroid cultured human dermal papilla cells. Biosci Biotechnol Biochem. 2017:81:2323-9.

Cotsarelis G, Sun T, Lavker RM. Label-retaining cells reside in the bulge area of pilosebaceous unit: implications for follicular stem cells, hair cycle, and skin carcinogenesis. Cell. 1990;61:1329-37.

Ehama R, Ishimatsu-Tsuji Y, Iriyama S, Ideta R, Soma T, Yano K, Kawasaki C, Suzuki S, Shirakata Y, Hashimoto K. Hair follicle regeneration and human cells using grafted rodent and human cells. J Invest Dermatol. 2007;127:2106-15.

Guo W, Flanagan J, Jasuja R, Kirkland J, Jiang L, Bhasin S. The effects of myostatin on adipogenic differentiation of human bone marrow-derived mesenchymal stem cells are mediated through cross-communication between Smad3 and Wnt/beta-catenin signaling pathway. J Biol Chem. 2008;283:9136-45.

Harel S, Higgins CA, Cerise JE, Dai Z, Chen JC, Clynes R, Christiano AM. Pharmacologic inhibition of JAK-STAT signaling promotes hair growth. Sci Adv. 2015;23:e1500973.

Kang BM, Shin SH, Kwack MH, Shin H, Oh JW, Kim J, Moon C, Moon C, Kim JC, Kim MK, Sung YK. Erythropoietin promotes hair shaft growth in cultured human hair follicles and modulates hair growth in mice. J Dermatol Sci. 2010;59:86-90

Kishimoto J, Burgeson RE, Morgan BA. Wnt signaling maintains the hair-inducing activity of the dermal papilla. Genes Dev. 2000;14:1181-5.

Millar SE. Molecular mechanisms regulating hair follicle development. J Invest Dermatol. 2002;118:216-25.

Millar SE, Willert K, Salinas PC, Roelink H, Nusse R, Sussman DJ, Barsh GS. WNT signaling in the control of hair growth and structure. Dev Biol. 1999;207:133-49.

Miranda-Vilela AL, Botelho AJ, Muehlmann LA. An overview of chemical straightening of human hair: technical aspects, potential risks to hair fibre and health and legal issues. Int J Cosmet Sci. 2014;36:2-11.

Ohyama M, Zheng Y, Paus R. The mesenchymal component of hair follicle neogenesis: background, methods and molecular characterization. Exp Dermatol. 2010:19:89-99.

Paus R, Cotsarelis G. The biology of hair follicles. N Engl J Med. 1999;341:491-7. Rendl M, Polak L, Fuchs E. BMP signaling in dermal papilla cells is required for their hair follicle-inductive properties. Genes Dev. 2008;15:543-57.

Schmidt-Ullrich R, Paus R. Molecular principles of hair follicle induction and morphogenesis. BioEssays. 2005;27:247-61.

Soma T, Fujiwara S, Shirakata Y. Hair-inducing ability of human dermal papilla cells cultured under Wnt/beta-catenin signaling activation. Exp Dermatol. 2012;21:307-9

Telerman SB, Rognoni E, Sequeira I, Pisco AO, Lichtenberger BM, Culley OJ, Viswanathan P, Driskell RR, Watt FM. Dermal Blimp1 acts downstream of epidermal TGF $\beta$ and WNT/B-catenin to regulate hair follicle formation and growth. J Invest Dermatol. 2017;137:2270-81.

Yang CC, Cotsarelis G. Review of hair follicle dermal cells. J Dermatol Sci. 2010;57:2-11.

Ready to submit your research? Choose BMC and benefit from:

- fast, convenient online submission

- thorough peer review by experienced researchers in your field

- rapid publication on acceptance

- support for research data, including large and complex data types

- gold Open Access which fosters wider collaboration and increased citations

- maximum visibility for your research: over $100 \mathrm{M}$ website views per year

At $\mathrm{BMC}$, research is always in progress.

Learn more biomedcentral.com/submissions 